\title{
A DIMENSÃO ECONÔMICA DA JUSTIÇA IGUALITÁRIA: A DEMOCRACIA DE CIDADÃOS-PROPRIETÁRIOS NA TEORIA DA JUSTIÇA DE RAWLS
}

\author{
Sylvio Alarcon ${ }^{1}$
}

\begin{abstract}
Resumo: Este artigo apresenta e discute a democracia de cidadãos-proprietários como o sistema socioeconômico mais adequado à realização dos princípios da teoria da justiça de John Rawls.

Palavras-chave: democracia de cidadãos-proprietários - igualitarismo - justiça - propriedade Rawls.
\end{abstract}

\section{Introdução}

Ao tomar conhecimento dos principais aspectos da teoria da justiça de John Rawls, poderíamos supor, em uma reflexão inicial, que o Estado ideal para acomodar uma sociedade justa no sentido rawlsiano seria um Estado de bem-estar social, acolhedor do sistema capitalista e preenchido com políticas sociais redistributivas. Em verdade, essa impressão não é corriqueira apenas entre aqueles que iniciam seus estudos da obra de Rawls: incorreram na mesma suposição destacados adeptos e críticos de Rawls, e isto durante longo tempo, até que o próprio filósofo se encarregasse de desfazer expressamente a associação entre sua teoria da justiça e o Estado de bem-estar social.

De fato, essa primeira impressão é afastada ao se atentar para o fato de que as exigências distributivas da teoria da justiça de Rawls são diferentes das políticas levadas a efeito nos Estados de bem-estar social existentes. Rawls, como dito, se encarregou de evitar qualquer engano a esse respeito e expressou seu - digamos - descontentamento profundo ao que chamou de "capitalismo de bem-estar social" (welfare capitalism), afirmando categoricamente que o "capitalismo de bem-estar rejeita o valor equitativo da liberdade política, e, mesmo tendo alguma preocupação com a igualdade de oportunidade, as políticas necessárias para alcançá-la não são seguidas. Isso cria desigualdades muito grandes na propriedade (meios de produção e recursos naturais), de sorte que o controle da economia e de muito da vida política ficam nas mãos de poucos. E embora, como o nome 'capitalismo de bem-estar' sugere, provisões de bem-estar possam ser bastante generosas e

\footnotetext{
${ }^{1}$ Doutor em Direito pela Universidade de São Paulo. Professor da Faculdade de Direito da Universidade Católica de Santos.
} 
garantir um mínimo social cobrindo as necessidades básicas, um princípio de reciprocidade para regular desigualdades econômicas e sociais não é reconhecido"”.

Como fica claro, para Rawls o sistema socioeconômico adequado à concretização de seus princípios de justiça não é o sistema capitalista com conformações de bem-estar social - ou outros sistemas sócio-econômicos tradicionais, como o capitalismo "laissezfaire" e o comunismo, como veremos -, mas dois sistemas diferentes: a democracia de cidadãos-proprietários (property-owning democracy) e o socialismo liberal. Segundo Rawls, ambos os sistemas são, em tese, igualmente aptos a realizar seus princípios de justiça, e a escolha entre ambos deve ser feita atendendo antes às circunstâncias históricas e culturais e à tradição política de dada sociedade do que às virtudes ou defeitos dos dois sistemas. Neste trabalho, analisarei apenas a democracia de cidadãos-proprietários, seja porque o próprio Rawls se ocupou dela com maior detença, seja porque a idéia está mais próxima da tradição do pensamento político ocidental, sobretudo norte-americano, seja porque - como adverte $\mathrm{O}^{\prime} \mathrm{Neill}^{3}$ - as diferenças entre democracia de cidadãos-proprietários e o socialismo liberal são menores do que as denominações sugerem.

Pois bem. A ideia de democracia de cidadãos-proprietários, conquanto caia como uma luva na teoria da justiça de Rawls, não foi criada pelo filósofo americano, mas pelo economista inglês James E. Meade, em um texto originalmente publicado em 1964 ${ }^{4}$. A democracia de cidadãos-proprietários, em resumo, não implica a distribuição equitativa da propriedade privada entre todos os cidadãos, ou a abolição da propriedade privada e a instituição da propriedade pública, mas uma dispersão da propriedade privada entre os cidadãos, por meio de políticas de redistribuição ex ante das riquezas produzidas pelos cidadãos e trazidas ao mercado.

Segundo Rawls, "a democracia de cidadãos-proprietários garante as liberdades básicas juntamente com o valor equitativo das liberdades políticas e a igualdade de oportunidades, e regula as desigualdades econômicas e sociais por um princípio de mutualidade, se não pelo princípio da diferença". ${ }^{5}$ Em resumo: diferentemente do que se poderia pensar, a democracia de cidadãos-proprietários não implica a coletivização da propriedade privada dos meios de produção, mas traz consequências para a estrutura básica da sociedade e para as instituições de fundo, dispersando a propriedade de riqueza e capital e impedindo, dessa forma, que uma pequena parte da sociedade possa controlar a economia e também, indiretamente, a vida política.

\footnotetext{
2 RAWLS, Justice as fairness, p. 137-138.

3 Cf. O’NEILL, "Free (and fair) markets without capitalism: political values, principles of justice, and property-owning democracy", p. 76.

${ }^{4}$ Cf. MEADE, Efficiency, equality, and the ownership of property.

${ }^{5}$ Cf. RAWLS, Justice as fairness, p. 138-139.
} 
O objetivo deste breve texto consiste em destacar e discutir as conexões existentes entre a democracia de cidadãos-proprietários e os princípios ralwsianos de justiça. Pretende-se demonstrar que, apesar do caráter especulativo da exposição de Rawls sobre a democracia de cidadãos-proprietários, a rejeição do capitalismo de bem-estar social e a defesa da democracia de cidadãos-proprietários como o sistema socioeconômico mais adequado à promoção da justiça devem-se à coerência firme de Rawls com seus princípios de justiça. Também se pretende demonstrar que a argumentação de Rawls quanto ao ponto, em que pese sua habitual consistência, não está imune a críticas. Mesmo assim, a ideia de democracia de cidadãos-proprietários permanece altamente atrativa do ponto de vista da teoria da justiça, contrastando, curiosamente, com o interesse relativamente pequeno a seu respeito, no âmbito da teoria política contemporânea. Objetiva-se contribuir com o debate acerca da democracia de cidadãos-proprietários no Brasil, procedendo a uma revisão, conquanto sintética, da literatura existente a respeito desse tema.

\section{Contextualizando: a democracia de cidadãos-proprietários na teoria da justiça de Rawls}

Antes de iniciarmos a análise da democracia de cidadãos proprietários na teoria da justiça de Rawls, convém rememorar alguns pontos destas que interessam mais de perto ao tema.

\subsection{Justiça igualitária e os princípios de justiça}

A concepção geral de justiça de Rawls consiste em uma ideia central, que o próprio filósofo sintetiza: "Todos os bens sociais - liberdade e oportunidade, renda e riqueza, e as bases do auto-respeito - devem estar distribuídos igualmente na sociedade, a menos que uma distribuição desigual de alguns ou de todos esses bens seja feita em favor dos menos

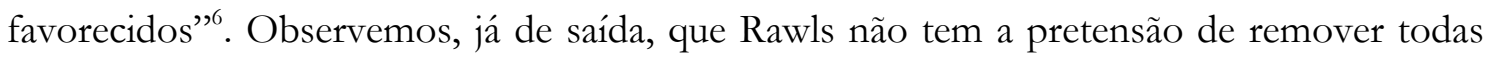
as desigualdades sociais, mas apenas aquelas que tornam determinadas pessoas menos favorecidas do que outras. Como explica Kymlicka, "[d]esigualdades são permitidas se elas melhoram minha condição inicial de igualdade, mas não são admitidas se, como no utilitarismo, elas invadem minha condição justa"'. Alguma desigualdade, portanto, é admitida, desde que sua existência traga benefícios para os menos favorecidos.

Essa concepção, todavia, não nos diz tudo o que é necessário para se chegar a uma teoria da justiça. Ela deixa em aberto, fundamentalmente, a questão de como os bens primários sociais devem estar distribuídos na sociedade. Por isso, Rawls tratou de orientar

${ }^{6}$ Cf. Id., A theory of justice, p. 54.

${ }^{7}$ Cf. KYMLICKA, Contemporary political philosophy, p. 55. 
essa concepção geral de acordo com dois princípios. O primeiro princípio nos diz que toda pessoa deve ter o direito igual ao mais amplo sistema de liberdades básicas iguais que for compatível com o mesmo sistema amplo de liberdades básicas de todas as outras pessoas. O segundo princípio nos diz que as desigualdades sociais e econômicas devem ser arranjadas de maneira que ambas, ao mesmo tempo, tragam vantagens aos menos favorecidos na maior medida possível, e vinculem-se a cargos e posições abertas a todos, sob as condições de igualdade equitativa de oportunidades.

Esses três imperativos são, de acordo com Rawls, lexicamente ordenados, ou seja, em primeiro lugar as liberdades básicas devem ser plenamente satisfeitas, em seguida a igualdade equitativa de oportunidades e, por fim, o princípio da diferença.

Com fica claro, de acordo com esses princípios alguns bens sociais são mais importantes do que outros, e não podem ser sacrificados em nome desses outros bens - as chamadas "liberdades básicas", como liberdade religiosa, de expressão e de associação, por exemplo, têm precedência sobre outros tipos de liberdades. Analisemos mais de perto os dois princípios de justiça da teoria ralwsiana, bem como suas implicações.

O primeiro princípio é forte e evidentemente conectado com a ideia de liberdade. As liberdades básicas a que se refere são necessárias para caracterizar a ideia moral de pessoas livres e iguais, definindo um tipo ideal democrático de cidadão que tem um status cívico com poderes para influenciar, de maneira justa e efetiva, a vida política pública ${ }^{8}$. Note-se, porém, que o primeiro princípio se refere a liberdades básicas. Rawls, com isso, recorre à consideração de que algumas liberdades são mais importantes do que outras, e menciona expressamente cinco delas: liberdade de consciência e de pensamento; liberdade de associação; liberdades políticas; direitos e liberdades que protegem a integridade e liberdades pessoais (nas quais se inclui a liberdade de ocupação e o direito de propriedade); e as liberdades encampadas pelo Estado de Direito?.

Já o segundo princípio determina como a distribuição dos recursos da sociedade será feita. Esse princípio, porém, não implica a ideia de justiça distributiva de renda e riqueza, presente nas sociedades contemporâneas, segundo a qual o que cada pessoa obtém é justo se os benefícios ou posições em questão também forem acessíveis aos demais. Importa assinalar que a teoria da justiça de Rawls não admite que alguém mereça seus maiores talentos ou capacidades, isto é, ninguém é merecedor dos prêmios e das vantagens que a "loteria natural" lhes deu. Por isso, o esquema rawlsiano de justiça não se satisfaz com a mera igualdade de oportunidades, ao contrário, diz que as maiores vantagens dos mais beneficiados pela loteria natural (e a permanência da desigualdade que isto implica)

${ }^{8}$ Cf. FREEMAN, Rawls, p. 45.

${ }^{9}$ Cf. RAWLS, Political liberalism, p. 291. 
apenas são justificáveis se elas fizerem parte de um sistema distributivo que implica a melhoria das condições dos membros menos favorecidos da sociedade ${ }^{10}$.

Ainda a respeito desses dois princípios, Rawls se encarregou de estabelecer regras de prioridade entre eles. A "prioridade da liberdade" nos diz que os princípios de justiça devem ser elencados em uma ordem léxica e, por isso, as demandas de liberdade devem ser satisfeitas primeiro, e a liberdade pode ser restringida apenas em nome da própria liberdade. Já a chamada "prioridade da liberdade sobre a eficiência e o bem-estar" nos diz que o segundo princípio de justiça tem prioridade léxica sobre o princípio da eficiência e sobre o princípio da maximização da somatória das vantagens, e que a igualdade equitativa de oportunidade tem prioridade sobre o princípio da diferença.

Importante lembrar ainda que Rawls tem dois argumentos para justificar os princípios de justiça tal como os delineou. Primeiro, sustenta que, diferentemente da ideologia prevalecente em matéria de justiça distributiva, que enfatiza o ideal de igualdade de oportunidades, sua teoria se adequa melhor às instituições concernentes à justiça e define melhor todos os ideais de justiça do que a ideologia rival. E segundo, Rawls justifica o conteúdo específico de cada princípio recorrendo à ideia de contrato social hipotético, ou seja, Rawls assume que, se em um estado pré-social as pessoas tivessem que decidir os princípios que governariam sua sociedade (estando na chamada "posição original"), elas escolheriam os princípios de Rawls ${ }^{11}$, porque teriam o interesse racional em adotar esses princípios para presidir a cooperação social ${ }^{12}$.

\subsection{Princípios de justiça e a estrutura básica da sociedade}

Os princípios de justiça delineados por Rawls têm uma aplicação específica: a chamada "estrutura básica da sociedade". Rawls explica que "[o] objeto primário da justiça é a estrutura básica da sociedade ou, mais exatamente, o modo como as instituições sociais mais importantes distribuem os direitos e deveres fundamentais, e determinam a divisão das vantagens provenientes da cooperação social. Por instituições mais importantes, entendo a constituição política e as principais disposições econômicas e sociais" ${ }^{\prime 13}$.

A partir dessa definição, sobretudo do ponto em que Rawls destaca a função das instituições sociais, fica evidente que a estrutura básica da sociedade interessa fortemente à análise da democracia de cidadãos-proprietários, porque ela é - digamos - um modo de ser, uma característica, uma conformação da estrutura básica. O sistema econômico determina

\footnotetext{
${ }^{10}$ Cf. GARGARELLA, As teorias da justiça depois de Rawls, p. 25-26.

${ }^{11}$ Cf. RAWLS, $A$ theory of justice, p. 10-11.

${ }^{12}$ Cf. KYMLICKA, Contemporary political philosophy, p. 57.

${ }^{13}$ Cf. RAWLS, $A$ theory of justice, p. 6.
} 
diretamente a distribuição dos direitos e dos deveres fundamentais dos cidadãos, bem como - e mais evidentemente - a divisão das vantagens oriundas da cooperação social.

Os princípios de justiça devem conformar e informar essa estrutura básica, guiando e orientando as instituições políticas de maneira a fazê-las produzir decisões, resultados e efeitos considerados justos, tendo como referencial os princípios delineados no tópico anterior. $\mathrm{Na}$ definição simples porém precisa de Freeman, a estrutura básica da sociedade é composta pelo arranjo de instituições políticas, sociais e econômicas que tornam a cooperação social possível e produtiva. É essa necessidade de cooperação social produtiva, atendida pelas instituições, que as distingue na estrutura básica da sociedade ${ }^{14}$.

Quando as instituições que produzem desigualdades econômicas e compõem a estrutura básica da sociedade satisfazem os dois princípios de justiça, estamos diante de uma situação de justiça procedimental pura, em que quaisquer titulares, estados de coisas e perfis distributivos que sob ela se produzam deverão ser considerados justos ${ }^{15}$. O interesse de Rawls acerca da democracia de cidadãos-proprietários, com sua estrutura básica peculiar, que delinearemos a seguir, parece ser uma tentativa de estabelecer uma recondução da crítica aos trilhos de sua teoria da justiça, com a ênfase na questão da dispersão da riqueza e da renda, promovida pela estrutura básica da sociedade democrática de cidadãosproprietários como uma situação de justiça procedimental pura.

\section{O princípio da diferença e a estrutura básica da sociedade}

Feitas essas considerações gerais sobre os pontos da teoria rawlsiana da justiça que interessam ao presente estudo, passo ao problema do princípio da diferença aplicado à estrutura básica da sociedade. Ele não é o único princípio de justiça que se aplica à estrutura básica; ao contrário, também o primeiro princípio e a segunda parte do segundo princípio também informam e conformam a estrutura básica da sociedade ${ }^{16}$.

Como adiantado no início, as exigências da teoria da justiça de Rawls não são plenamente satisfeitas com as políticas públicas levadas a efeito nos Estados de bem-estar social. E é o princípio da diferença que torna as demandas distributivas muito mais exigentes, porque ele impõe que as instituições jurídicas que moldam o direito de propriedade e de contrato e as instituições econômicas que tornam possível a produção, o comércio e consumo, devem ser organizadas da perspectiva dos economicamente menos favorecidos. Como esclarece Samuel Freeman, "[m]ais do que organizar um sistema econômico que promova de maneira ótima algum outro valor (eficiência, utilidade agregada, liberdade de escolha, etc.) e então permita a esses benefícios atingirem os pobres

\footnotetext{
${ }^{14}$ Cf. FREMAN, p. 101-102.

${ }^{15}$ Cf. VITA, A justiça igualitária e seus críticos, p. 260.

${ }^{16}$ Cf., em maiores detalhes, FREEMAN, Rawls, p. 103-104.
} 
[...] o princípio da diferença foca primeiro nas perspectivas dos menos favorecidos, ao determinar o sistema de propriedade e controle, produção e troca. Um sistema econômico é mais justo que outro na medida que promove mais os interesses dos menos favorecidos" ${ }^{\prime 1}$.

É por isso que o princípio da diferença se aplica às instituições, não às pessoas, o que não quer dizer que não crie, indiretamente, deveres para estas, mas somente que, em primeiro lugar, e diretamente, o princípio da diferença informa e conforma as convenções econômicas e as instituições jurídicas - pensemos, por exemplo, na regulação jurídica da propriedade, do contrato, da tributação, das heranças etc. Lembrando que as instituições mais elementares fazem parte da estrutura básica da sociedade, podemos concluir que o princípio da diferença tem um grande papel a desempenhar na organização desta. De fato, o princípio da diferença não é o único que se aplica à estrutura básica, visto que os princípios concernentes às liberdades básicas e à igualdade equitativa de oportunidades também se referem a ela - o primeiro é essencial para a modelagem da Constituição, e o segundo se aplica marcadamente às instituições econômicas. O próprio Rawls assinalou que o primeiro sujeito da justiça são as instituições básicas, que tornam possível a cooperação social. $^{18}$

Também é claro que há muitas maneiras diferentes de organizar a estrutura básica da sociedade, com instituições básicas combinadas de modo diverso, produzindo formas de cooperação social muito distintas entre si. Em qualquer caso, porém, o papel principal do princípio da diferença é aplicar-se para especificar as formas de propriedade e direitos e responsabilidades concernentes à propriedade, assim como às transações permitidas e proibidas no sistema econômico ${ }^{19}$.

Diante do exposto, cabe perguntar: quais são as implicações do princípio da diferença aplicado à estrutura básica da sociedade e às instituições que a compõem? Em suma, essas implicações se referem à conformação das instituições econômicas, que devem ser desenhadas de maneira que os menos favorecidos aproveitem uma maior parcela de renda, riqueza e poder econômico mais geral do que em qualquer outro arranjo econômico. Em outras palavras, o princípio da diferença impõe a implementação de um sistema econômico que maximize os benefícios obtidos pelos menos privilegiados e que prossiga continuamente aumentando os resultados produtivos do sistema desde que isto beneficie os menos privilegiados. Com isso, fica claro que a exigência do princípio da diferença não é apenas o crescimento econômico contínuo por gerações, que simplesmente maximize indefinidamente as expectativas dos menos favorecidos, medidas em termos de renda e riqueza. É preciso que aquele crescimento econômico e essa maximização de expectativas

${ }^{17}$ Cf. FREEMAN, Rawls, p. 99.

${ }^{18}$ Cf. RAWLS, $A$ theory of justice, p. 6.

${ }^{19}$ Cf. FREEMAN, Rawls, p. 103. 
seja acompanhado também por compartilhamento de poder econômico e de auto-respeito. Um dos sistemas econômicos que Rawls cogita para atender ao princípio da diferença nesses termos é a democracia de cidadãos-proprietários, de que nos ocuparemos a seguir.

Para encerrar a seção, note-se que o princípio da diferença fornece um critério diverso do critério da eficiência, o critério liberal clássico da justiça distributiva, para decidir a divisão da renda e da riqueza resultante das alocações de mercado dos recursos produtivos e do resultado da produção. O princípio da diferença exige que as instituições econômicas sejam arranjadas de sorte que às classes menos beneficiadas aproveitem parcelas maiores de renda, riqueza e poder econômico, do que lhes aproveitaria em qualquer outro sistema econômico. Se pensarmos em um continuum de sistemas econômicos que inicia com o libertarianismo e, gradativamente, chega ao comunismo de economia dirigida, o princípio da diferença diz ser preferível o sistema econômico cujas instituições econômicas e jurídicas melhoram a condição das classes menos beneficiadas, em termos de compartilhamento de renda, riqueza, poder econômico e posições profissionais, do que qualquer outro sistema econômico do continuum. E, na avaliação de Rawls, dos sistemas socioeconômicos que cogita, os dois únicos que estão aptos a realizar o princípio da diferença - e também os outros princípios de justiça - são o socialismo liberal e a democracia de cidadãos-proprietários. Os menos favorecidos estarão melhores em termos de poder econômico e renda e riqueza em um desses dois sistemas sócio-econômicos do que no sistema capitalista de bem-estar social ou em qualquer outro sistema capitalista ou socialista.

\section{Justiça igualitária e os sistemas sócio-econômicos: a avaliação de Rawls}

Como dito, a exigência dos princípios rawlsianos de justiça, sobretudo o princípio da diferença, não é simplesmente o aumento das vantagens dos menos favorecidos, medidas em termos de renda e riqueza, mas o incremento global de sua condição econômica, o que vai além daqueles dois fatores. Segundo Freeman, essa ideia, presente já na primeira edição de "Uma teoria da justiça", foi largamente entendida como uma justificativa para o Estado capitalista de bem-estar social. ${ }^{20}$ Mas Rawls não tinha em mente exatamente esse sistema sócio-econômico quando cogitou o princípio da diferença aplicado às instituições econômicas, como fica claro no Prefácio da edição revisada de Uma teoria da justiça. Nele, Rawls expressamente trata de distinguir os sistemas socioeconômicos que considera adequados para concretizar sua teoria da justiça - que são a democracia de cidadãos-proprietários e o socialismo liberal - do Estado de bem-estar social. ${ }^{21}$ Como já adiantado, a questão relativa a qual desses dois sistemas sócio-econômicos é o mais justo

${ }^{20}$ Id., ibid., p. 114.

${ }^{21}$ Cf. RAWLS, $A$ theory of justice, p. XIV-XV. 
fica em aberto, porque Rawls considera ambos igualmente aptos, ao menos em tese, a concretizar seus princípios de justiça. A escolha entre a democracia de cidadãosproprietários e o socialismo liberal é questão dependente, antes, das circunstâncias históricas e culturais e da tradição do pensamento político de cada sociedade. ${ }^{22}$

Em outro texto ${ }^{23}$, a avaliação de Rawls sobre a adequação dos sistemas econômicos à sua teoria da justiça é mais precisa. Rawls distingue cinco sistemas econômicos, consideradas suas instituições políticas, econômicas e sociais: (a) capitalismo laissez-faire; (b) capitalismo de bem-estar social; (c) socialismo estatal com economia dirigida; (d) democracia de cidadãos-proprietários; e (e) socialismo liberal (e democrático) ${ }^{24}$. $\mathrm{Na}$ avaliação de Rawls, assumindo que suas instituições funcionam de maneira ideal, todos esses sistemas, com exceção do socialismo liberal e a democracia de cidadãos-proprietários, não são satisfatórios do ponto de vista de sua teoria da justiça, pelas razões que exporei muito brevemente, centrando mais na crítica ao capitalismo de bem-estar social.

O capitalismo "laissez-faire" não é satisfatório porque assegura somente uma igualdade formal, além de rejeitar tanto o valor equitativo das liberdades políticas como a igualdade equitativa de oportunidades. O objetivo principal desse sistema socioeconômico, segundo Rawls, corresponde à eficiência e ao crescimento econômicos, limitados somente por um mínimo social bem pequeno. ${ }^{25}$

Já o socialismo estatal, com a economia dirigida por um partido político, é um sistema sócio-econômico que viola o primeiro princípio de justiça - a igualdade de direitos e liberdades básicas -, além de não reconhecer o valor equitativo dessas liberdades. Nesse sentido, uma economia dirigida seria aquela guiada por um plano econômico geral, adotado pelo centro fazendo uso de pouco ou nenhum procedimento democrático ou de mercado. ${ }^{26}$

Por fim, para Rawls, o capitalismo de bem-estar social também rejeita o valor equitativo das liberdades políticas e, conquanto tenha alguma preocupação com a igualdade de oportunidades, disto não se seguem as políticas públicas necessárias para alcançá-la. Ainda segundo Rawls, o capitalismo de bem-estar social permite desigualdades muito grandes no tocante à propriedade real (meios de produção e recursos naturais), de maneira que o controle da economia e de grande parcela da vida política ficam nas mãos de uns poucos. Por fim, Rawls aponta que, apesar de o capitalismo de bem-estar social encampar provisões que garantem um mínimo social decente, cobrindo as necessidades básicas, ele não reconhece o princípio da reciprocidade na regulação da economia e das desigualdades sociais $^{27}$.

${ }^{22}$ Id., ibid., p. 248.

23 Cf. RAWLS, Justice as fairness.

${ }^{24}$ Id., ibid., p. 136.

${ }^{25}$ Id., ibid., p. 137; também RAWLS, A theory of justice, p. 12 e 17.

${ }^{26}$ Cf. RAWLS, Justice as fairness, p. 138.

${ }^{27}$ Id., ibid., p. 137-138. 
É importante examinar as críticas de Rawls ao capitalismo de bem-estar social um pouco mais de perto. Rawls reconhece que esse sistema sócio-econômico implica algum avanço que satisfaz, em alguma medida, suas demandas de justiça (garantia do mínimo social que satisfaz as necessidades básicas, por exemplo), mas também identifica uma série de limitações estruturais concernentes às capacidades de as instituições do capitalismo de bem-estar social darem conta de promover os princípios de justiça. Nesse sentido, as críticas de Rawls podem ser resumidas em três pontos.

Em primeiro lugar, o capitalismo de bem-estar social rejeita o valor equitativo das oportunidades políticas, violando assim o primeiro princípio da justiça, que demanda não apenas que a todos os cidadãos seja formalmente assegurado um sistema tão amplo de liberdades básicas quanto compatível com o reconhecimento do mesmo sistema abrangente a todos os outros cidadãos, mas também a garantia do valor equitativo dessas liberdades políticas. Tais liberdades são condições sociais prévias para a busca da política democrática, na medida em que asseguram a oportunidade para a aplicação livre e bem informada dos princípios de justiça à estrutura básica e à sua política por meio do exercício pleno e efetivo do senso de justiça dos cidadãos. ${ }^{28}$ Conclui-se que, a respeito do primeiro princípio de justiça, Rawls nega não que o capitalismo de bem-estar social possa promover proteção formal às liberdades básicas, mas a sua capacidade de proteger o valor equitativo das liberdades políticas. Assim, como assinalada O’Neill ${ }^{29}$, esse sistema socioeconômico é capaz de satisfazer o primeiro princípio apenas em um sentido fraco ou superficial, não podendo satisfazer genuinamente as demandas do princípio porque não é capaz de conferir aos cidadãos o valor real subjacente ao emprego daquelas liberdades na esfera política.

Em segundo lugar, o capitalismo de bem-estar social mostra-se insuficiente para alcançar a igualdade de oportunidades, violando assim a primeira parte do segundo princípio de justiça. Importante lembrar que, para Rawls, a igualdade de oportunidades é altamente exigente, não sendo suficiente que os cargos e empregos públicos estejam abertos a todos em um sentido formal. É necessário, para atender a esse princípio, que todos tenham a chance igual de ocupá-los, significando isto que aqueles que estão no mesmo nível de talento e capacidade e estão igualmente empenhados em utilizá-los devem ter a mesma perspectiva de sucesso independentemente de sua classe social de origem. ${ }^{30}$ Trata-se de um reclamo de justiça realmente exigente, porque visa quebrar o possível condicionamento das chances de sucesso dos indivíduos por sua condição social.

Por fim, em terceiro lugar, o capitalismo de bem-estar social, diz Rawls, também é incapaz de respeitar o princípio da reciprocidade e o princípio da diferença, provendo

\footnotetext{
${ }^{28}$ Id., ibid., p. 112-113.

${ }^{29}$ Cf. O’NEILL, "Free (and fair) markets without capitalism: political values, principles of justice, and property-owning democracy", p. 77-78.

${ }^{30}$ Cf. RAWLS, Justice as fairness, p. 44.
} 
apenas um mínimo social, violando assim a segunda parte do segundo princípio de justiça. Novamente, a crítica não atribui apenas ao capitalismo de bem-estar social a incapacidade de realizar em certa medida o princípio da diferença (para Rawls, a mais alta expressão do princípio da reciprocidade), mas a sua incapacidade total de alcançar um patamar sequer próximo desse paradigma, ao falhar em levar suficientemente a sério o valor igualitário da reciprocidade na vida econômica. A reciprocidade, importa lembrar, exige que os ganhos dos mais favorecidos da sociedade devam beneficiar os menos favorecidos. Como adverte O’Neill ${ }^{11}$, no capitalismo de bem-estar social, ou em qualquer regime que forneça apenas um mínimo social, ainda que generoso, tem-se a situação em que os ganhos dos mais favorecidos de um sistema de cooperação social ficam livres de qualquer relação de aproveitamento para com os menos favorecidos, violando assim o princípio da reciprocidade.

Assim, em conclusão, nenhum dos três regimes sócio-econômicos brevemente analisados aqui satisfaz às exigências impostas pelos princípios ralwsianos de justiça. Merece especial destaque a rejeição enérgica de Rawls ao capitalismo de bem-estar social, tido por diversos autores respeitáveis como o sistema ideal para promover os princípios de justiça, mas expressamente criticado e rejeitado por Rawls, que o considera insatisfatório à sua teoria, sobretudo do ponto de vista da segunda parte do segundo princípio de justiça.

Em contraste com os três regimes rejeitados por Rawls, tanto a democracia de cidadãos-proprietários como o socialismo liberal ensejam um arranjo constitucional para uma política democrática, garantem as liberdades básicas e o valor equitativo das liberdades políticas e a igualdade equitativa de oportunidades, e também regulam as desigualdades econômicas e sociais pelo (assim chamado por Rawls) princípio da mutualidade, se não, pelo princípio da diferença. ${ }^{32}$

Antes de passarmos ao exame da democracia de cidadãos-proprietários, cabe apenas mencionar a avaliação de Rawls quanto ao socialismo liberal. Rawls não diz muito sobre esse sistema socioeconômico, afirmando apenas que nele não há propriedade dos meios de produção pela sociedade - como no socialismo tradicional -, o poder político é compartilhado entre um número de partidos políticos democráticos e o poder econômico é disperso entre empresas, como quando, por exemplo, sua direção e administração é eleita pela sua própria força de trabalho, quando não é esta mesma quem as dirige e administra. Em contraste com a economia socialista dirigida, as empresas no socialismo liberal desenvolvem suas atividades sob um sistema de mercados livres e competitivos, e a liberdade de ocupação profissional também é assegurada. ${ }^{33}$

${ }^{31}$ Cf. O’NEILL, "Free (and fair) markets without capitalism: political values, principles of justice, and property-owning democracy", p. 78.

32 Cf. RAWLS, Justice as fairness, p. 138.

${ }^{33}$ Id., ibid. 


\section{A democracia de cidadãos-proprietários e os princípios de justiça}

\subsection{Introdução: definindo os contornos da democracia de cidadãos- proprietários}

Antes de passarmos à relação da democracia de cidadãos-proprietários com a teoria rawlsiana de justiça, é preciso definir, com a maior precisão possível, os contornos desse sistema socioeconômico que Rawls encara como "uma alterativa ao capitalismo". ${ }^{34}$ É preciso não perder de vista, em toda esta análise, que a abordagem de Rawls é assumidamente especulativa quanto ao ponto, ou seja, Rawls vê na democracia de cidadãosproprietários um regime sócio-econômico adequado, em tese, à promoção dos seus princípios de justiça; a possibilidade de uma democracia de cidadãos-proprietários real, com todas as contingências históricas e culturais possíveis, atender efetivamente a tal fim não preocupa Rawls.

A democracia de cidadãos-proprietários, como já destacamos, em verdade não foi idealizada por Rawls, mas por Meade ${ }^{35}$, de quem Rawls tomou emprestadas a terminologia e grande parte do conteúdo da ideia de um sistema sócio-econômico alternativo ao sistema capitalista. Muito resumidamente, a proposta de Meade preocupa-se com duas frentes: tributação e redistribuição de renda e riqueza. No primeiro campo, Meade defende a tributação forte da transmissão de riqueza entre gerações, mas também propõe igualmente a incidência de tributos sobre transferências de riquezas inter vivos, de sorte que ambas as formas de transmissão de riquezas, ao final, sejam tributariamente equivalentes. Ainda na esfera da tributação, Meade defende a redistribuição do capital em bases igualitárias amplas, juntamente com o aumento do gasto público com o desenvolvimento de capital humano através de educação e treinamento financiados com recursos públicos, o que revela a preocupação de Meade com a relação entre distribuição de capital humano e justiça distributiva. ${ }^{36}$ Já no campo da redistribuição de riqueza, Meade preocupa-se não somente com o compartilhamento de capital pecuniário (dinheiro), mas também, e sobretudo, a ampla dispersão da propriedade e do controle dos recursos produtivos, de forma a estimular a acumulação de pequenas propriedades. Um dos traços mais particulares da proposta de Meade consiste na ênfase à distribuição de riqueza, não apenas de renda, o que seria feito através da dispersão de pequenas propriedades (outro elemento importante) e de mecanismos que impeçam a acumulação de propriedades familiares entre gerações. Para colocar em prática a consecução desses objetivos, o sistema pensado por Meade é amplo e

\footnotetext{
${ }^{34}$ Id., ibid., p. 136.

${ }^{35}$ Cf. MEADE, Efficiency, equality, and the ownership of property.

36 Cf. O’NEILL, "Free (and fair) markets without capitalism: political values, principles of justice, and property-owning democracy", p. 79.
} 
complexo, incluindo desde transferências diretas, passando por políticas públicas de educação e moradia, até a intervenção governamental nos mercados financeiros, sempre em busca de um único objetivo político unificado e integrado.

Rawls se apropriou de grande parte das ideias de Meade acerca da democracia de cidadãos-proprietários na busca por um sistema econômico ideal para a concretização dos seus princípios de justiça. Como avalia O’Neill, Rawls deixou de lado certas "excentricidades" do modelo de Meade no tocante às políticas familiares, e enfatizou a dimensão democrática do modelo. O objetivo de Rawls com o delineamento de uma democracia de cidadãos-proprietários com similaridades estruturais ao modelo de Meade, explica o mesmo autor, foi de construir um sistema social que remediasse as falhas estruturais dos regimes capitalistas de bem-estar social, permitindo assim a realização de todas as partes dos seus dois princípios de justiça. ${ }^{37}$

Por meio da democracia de cidadãos-proprietários, Rawls enfatiza os valores políticos da liberdade, da igualdade e da democracia. Considera que esse sistema econômico assegura - importante lembrar - as liberdades básicas com o valor equitativo das liberdades políticas, bem como a igualdade equitativa de oportunidades, além de regular as desigualdades econômicas e sociais pelo princípio da mutualidade, se não pelo princípio da diferença ${ }^{38}$, ou seja, todos os desdobramentos dos princípios de justiça são atendidos. Tal como o capitalismo de bem-estar social, a democracia de cidadãos-proprietários assegura a propriedade privada dos meios de produção (diferentemente do sistema alternativo, o socialismo liberal ${ }^{39}$ ), mas, ao contrário do primeiro, a estrutura básica da sociedade na segunda funciona dispersando a propriedade de riqueza e capital e impedindo, dessa forma, que uma pequena parte da sociedade controle a economia e, indiretamente, também a vida política. ${ }^{40}$ Além de dispersar a propriedade da riqueza e do capital, vale lembrar que a democracia de cidadãos-proprietários implica, conforme a proposta de Meade, a dispersão também do capital humano. Tudo isso é feito por mecanismos redistributivos "ex ante", em oposição aos mecanismos do capitalismo de bem-estar social, que são "ex post". ${ }^{41}$ Segundo o próprio Rawls, a pretensão da democracia de cidadãos-proprietários não é apenas assistir àqueles menos favorecidos por acidentes ou má-fortuna (embora isto também deva ser feito), mas colocar todos os cidadãos em posição de administrar seus próprios negócios em um grau adequado de igualdade social e econômica. Os menos beneficiados não são desafortunados, que merecem caridade, compaixão e pena, mas pessoas a quem é devida

\footnotetext{
${ }^{37}$ Id., ibid., p. 80.

38 Cf. RAWLS, Justice as fairness, p. 138.

${ }^{39}$ Uma interessante análise da propriedade pública e também das perspectivas atuais do socialismo encontrase em ROEMER, "On public ownership".

${ }^{40}$ Cf. RAWLS, Justice as fairness, p. 139.

41 Cf. O’NEILL, "Free (and fair) markets without capitalism: political values, principles of justice, and property-owning democracy”, p. 80.
} 
reciprocidade, como um problema de justiça política entre cidadãos que são livres e iguais como todos os outros. ${ }^{42}$

Em conclusão, e seguindo a leitura de $\mathrm{O}^{\prime} \mathrm{Neill}^{43}$, devemos entender a democracia de cidadãos-proprietários como o sistema sócio-econômico adequado à teoria rawlsiana da justiça a partir de três questões centrais: (a) a ampla dispersão de capital, com cidadãos controlando parcelas substanciais e iguais do capital produtivo (incluindo capital humano e não-humano); (b) o impedimento da transmissão de vantagens entre gerações, mediante a tributação de heranças e doações, limitando as grandes desigualdades decorrentes delas em termos de riqueza; e (c) as salvaguardas contra a corrupção da política democrática, necessárias para limitar os efeitos da riqueza privada e corporativa na política, salvaguardas materializadas em mecanismos como o financiamento público de partidos políticos e de campanhas eleitorais e a provisão pública de fóruns para debates políticos, entre outros. Segundo O’Neill, a questão "c" relaciona-se com o primeiro princípio de justiça, ao enfatizar a proteção do valor equitativo das liberdades políticas; já as questões "a" e "b" relacionam-se com o segundo princípio de justiça; a integração das três questões resulta em um sistema sócio-econômico capaz de superar as limitações estruturais do capitalismo de bem-estar social e proporcionar um conjunto plenamente justo de arranjos socioeconômicos. ${ }^{44}$

Definidas as características elementares da democracia de cidadãos-proprietários, podemos passar ao exame desse sistema sócio-econômico à luz de cada um dos princípios rawlsianos de justiça, em busca das conexões existentes entre eles, e também das críticas passíveis de serem dirigidas à democracia de cidadãos-proprietários a partir dos princípios de justiça.

\subsection{Democracia de cidadãos-proprietários e a igualdade de liberdades básicas}

Comecemos, seguindo a ordem léxica que o próprio Rawls estabeleceu, pelo primeiro princípio de justiça, relacionado à igualdade de liberdades básicas, com especial atenção ao valor equitativo das liberdades políticas. Quanto a esse princípio, já destacamos que Rawls afirma que o capitalismo de bem-estar social rejeita o valor equitativo das liberdades políticas e permite uma desigualdade muito grande em termos de propriedade real, de maneira que o controle da economia e grande parte da vida política ficam nas mãos de uns poucos. ${ }^{45}$ Já a democracia de cidadãos-proprietários, diz Rawls, prestigia o primeiro

\footnotetext{
${ }^{42}$ Cf. RAWLS, Justice as fairness, p. 139

43 Cf. O’NEILL, "Free (and fair) markets without capitalism: political values, principles of justice, and property-owning democracy", p. 80-81.

${ }^{44}$ Id., ibid., p.81.

${ }^{45}$ Cf. RAWLS, Justice as fairness, p. 137-138.
} 
princípio na medida em que, essencialmente, limita os efeitos da riqueza no processo político - diminuindo, por exemplo, sua influência nas campanhas eleitorais, ao utilizar o financiamento público de campanha e restringir a contribuições privadas a candidatos; ou disponibilizando fóruns públicos para debate político entre programas políticos alternativos, etc.

Mas há quem discorde de Rawls acerca da necessidade da democracia de cidadãosproprietários para concretizar o primeiro princípio de justiça. O’Neill considera o argumento de Rawls em certa medida incompleto, porque Rawls não teria demonstrado cabalmente que o valor equitativo das oportunidades políticas somente pode ser assegurado em uma democracia de cidadãos-proprietários, e não em um regime capitalista de bem-estar social. ${ }^{46}$

\subsection{Democracia de cidadãos-proprietários e o valor equitativo das oportunidades}

Passemos, agora, à primeira parte do segundo princípio de justiça, relacionada com o valor equitativo das oportunidades. Trata-se, por assim dizer, do elemento intermédio da ordem léxica estabelecido por Rawls: tem precedência sobre o princípio da diferença (segunda parte do segundo princípio de justiça), mas não sobre o primeiro princípio de justiça (prioridade da liberdade).

A defesa da democracia de cidadãos-proprietários como o sistema sócio-econômico apto a promover o valor equitativo das oportunidades refere-se, na essência, à capacidade deste sistema de limitar a influência do contexto social sobre as chances de vida dos indivíduos. Para Rawls, o valor equitativo das oportunidades é atingido quando a influência de fatores sociais sobre a capacidade dos indivíduos para alcançar posições sociais específicas é neutralizada. Isso significa, em termos práticos, que aqueles que têm o mesmo nível de talento e habilidade e a mesma disposição para utilizá-las, mas provêm de contextos sociais diferentes, devem ter as mesmas perspectivas de sucesso, apesar dessa diferença social de origem ${ }^{47}$. Para produzir esse tipo de resultado, a democracia de cidadãos-proprietários possui instituições que restringem a transmissão da riqueza, seja pela via da herança, seja da doação inter vivos, mas em qualquer caso mediante a tributação, que impede a transferência intergeracional de vantagens. O'Neill chega a dizer que devemos aceitar que mecanismos dessa natureza são um elemento necessário de qualquer sistema sócio-econômico que esteja comprometido com o princípio da igualdade equitativa de

46 Cf. O’NEILL, "Free (and fair) markets without capitalism: political values, principles of justice, and property-owning democracy", p. 84.

47 Cf. RAWLS, Political liberalism, p. 44. 
oportunidades. ${ }^{48}$ Freeman também lembra que cobertura de assistência de saúde universal é essencial à democracia de cidadãos-proprietários, assim como um sistema universal de saúde, como exigências concernentes à igualdade equitativa de oportunidades. ${ }^{49}$

Além disso, Freeman ${ }^{50}$ também lembra que, na democracia de cidadãosproprietários, os trabalhadores não são encorajados a trabalhar interessados apenas em seus salários, mas também no produto de seu trabalho. Eles têm a oportunidade de possuir e controlar o capital que utilizam no exercício diário de suas próprias capacidades, além de incrementar o controle e a proteção de seus locais de trabalho.

De toda sorte, Rawls não admite a possibilidade de alguns membros da sociedade, estando aptos ao trabalho, deixarem de fazê-lo. Não se pode pretender obter as vantagens oriundas da cooperação social sem, estando apto para tanto, fazer parte desta cooperação. Opondo-se, nesse ponto, a van Parijs ${ }^{51}$, Rawls considera que a provisão de um mínimo social a todos os cidadãos, trabalhadores ou são, pode produzir dependência entre os menos beneficiados e gerar um sentimento de exclusão. Essa consideração de Rawls parece fazer ainda mais sentido se aplicada à democracia de cidadãos-proprietários, em que é absolutamente fundamental o papel dos trabalhadores para tornar justa a sociedade.

\subsection{Democracia de cidadãos-proprietários e o princípio da diferença}

Chegamos, por fim, à última parte do segundo princípio ralwsiano de justiça, concernente ao princípio da diferença, que prescreve, em síntese, que situações de desigualdade na distribuição de bens primários sociais se justificam somente se elas trazem vantagens aos membros menos beneficiados da sociedade. É importante lembrar que esse é o último elemento da ordem léxica de Rawls, mas nem por isso sua conexão com a democracia de cidadãos-proprietários deixa de ser relevante.

O problema das desigualdades sociais e econômicas não interessa à concepção rawlsiana de justiça como equidade apenas porque parece errado que alguns ou muitos indivíduos em uma sociedade tenham condições de vida sofríveis, inclusive em termos de fome e doenças, enquanto outros tantos contam com ampla assistência governamental. $\mathrm{O}$ problema das desigualdades sociais concerne também à dominação e ao respeito de uma parte da sociedade em face da outra. Segundo Rawls, quando esses dois tipos de desigualdades são grandes, tendemos a apoiar a desigualdade política, e esse tipo de poder permite a poucos, em virtude do seu controle sobre a máquina do Estado, instalarem um

\footnotetext{
48 Cf. O’NEILL, "Free (and fair) markets without capitalism: political values, principles of justice, and property-owning democracy", p. 85.

${ }^{49}$ Cf. FREEMAN, Rawls, p. 231.

${ }^{50}$ Id., ibid., p. 227.

${ }^{51}$ Cf. VAN PARIJS, "Basic income capitalism"; VAN PARIJS, Real freedom for all.
} 
sistema de leis e de propriedade que assegura sua posição dominante na economia como um todo. Além da questão da dominação, há o problema do respeito mútuo: desigualdades políticas e econômicas significativas geralmente são associadas com desigualdades de status social, que encorajam os menos favorecidos a serem vistos e verem a si mesmos como inferiores aos demais. Isso pode provocar atitudes largamente difundidas de deferência e subserviência, de um lado, e a vontade de dominação e arrogância, de outro. ${ }^{52}$

Tendo em conta essas razões pelas quais a desigualdade interessa à concepção de justiça como equidade, pergunta-se: qual é precisamente a relação da democracia de cidadãos-proprietários com o princípio da diferença? Esse sistema sócio-econômico atua no sentido de promover o princípio da diferença, mais uma vez, dispersando a propriedade e o controle dos meios de produção. Como Rawls mesmo explica, "a intenção [da democracia de cidadãos-proprietários] não é simplesmente assistir os que estão em desvantagem em razão de acidente ou má-fortuna (embora isto deve ser feito), mas, mais, colocar todos os cidadãos em posição de admitir seus próprios negócios em um grau adequado de cooperação política e social. Os menos beneficiados são desafortunados ou azarados [...] mas aqueles a quem é devida reciprocidade como uma questão de justiça política entre aqueles que são cidadãos livres e iguais como todos os outros" ${ }^{33}$.

É interessante notar, segundo Freeman ${ }^{54}$, que nesse ponto Rawls compartilha da crença de John Stuart Mill, segundo a qual a existência de uma única opção real dos trabalhadores para com seus empregados - a relação de salário - diminui a liberdade e a independência individuais, afrouxa suas personalidades e imaginações, diminui o respeito mútuo entre as classes assalariadas e conduz finalmente à perda do auto-respeito entre os trabalhadores. Por essa e outras razões, Rawls foi atraído por ideias como a "economia compartilhada"- em que os trabalhadores têm parte da propriedade do capital privado cooperativas de trabalho, provisões públicas para estimular os trabalhadores a se tornarem agentes econômicos independentes ou começarem seus próprios negócios, e outras medidas para dispersar a distribuição do controle dos meios de produção.

\section{Conclusão}

A democracia de cidadãos-proprietários, mais do que um conceito ou uma definição, é uma ideia, altamente cativante e relevante do ponto de vista da teoria rawlsiana da justiça, relacionando-se com a dimensão econômico-institucional da justiça igualitária. É claro, não se pode perder de vista que a abordagem de Rawls a seu respeito é altamente especulativa, e provavelmente, ao ser posta em prática, diversas relações entre os princípios

\footnotetext{
${ }^{52}$ Cf. RAWLS, Justice as fairness, p. 130-131.

${ }^{53}$ Id., ibid., p. 139.

${ }^{54}$ Cf. FREEMAN, Rawls, p. 447.
} 
de justiça e os mecanismos de dispersão de riqueza e renda desse regime sócio-econômico não seriam tão perfeitos quanto se apresentam na teoria, dando ensejo a críticas de ordem empírica. Rawls, porém, não parece exatamente preocupado com críticas dessa natureza; parece, antes, interessado em desvincular de sua teoria da justiça o capitalismo de bem-estar social e deixar claro que sua proposta não consiste, de forma alguma, em uma defesa desse sistema socioeconômico, muito menos que ele satisfaz - sequer razoavelmente - as exigências impostas pelos princípios rawlsianos de justiça. As conexões entre tais princípios e o arranjo da estrutura básica da democracia de cidadãos-proprietários certamente são fortes e estão firmemente traçadas pela teoria política normativa contemporânea, como procuramos resgatar neste texto. Talvez um passo seguinte rumo ao aprofundamento do tema possam ser abordagens empíricas de contextos reais, feitas à luz da ideia de democracia de cidadãos-proprietários e de suas relações com os princípios rawlsianos de justiça, como propôs Macedo ${ }^{55}$, em interessante análise da distribuição da riqueza e do poder político no plano local norte-americano. Abordagens dessa natureza podem elucidar não apenas inconsistências ou esperanças exageradas acerca da democracia de cidadãosproprietários, mas também revelar o quão desiguais efetivamente são determinados sistemas sócio-econômicos, nos planos nacional, regional e local. Em qualquer caso, se a democracia de cidadãos-proprietários não tem contornos definitivos e certezas conclusivas já no plano normativo, no plano fático sua realização parece ainda distante - se é que virá em um futuro próximo -, pois, como lembrou Vita ${ }^{56}$, a estrutura institucional que satisfaria, ainda que de forma aproximada, ao critério de justiça procedimental pura encartado na democracia de cidadãos-proprietários não corresponde a nada que conheçamos até o momento. Mesmo assim, não se pode em absoluto negligenciar tão frutífero tema, ainda que o profundo distanciamento entre a ideia e o plano concreto possa constituir um fator limitante da análise teórica da democracia de cidadãos-proprietários.

\section{THE ECONOMIC DIMENSION OF EGALITARIAN JUSTICE: THE PROPERTY- OWNING DEMOCRACY IN RAWLS' THEORY OF JUSTICE}

Abstract: This article presents and discusses the property-owning democracy as the most appropriate political system to realize the principles of John Rawls' theory of justice. Key-words: property-owning democracy - egalitarism - justice - property - Rawls.

${ }^{55}$ Cf. MACEDO, "Property-owning plutocracy: inequality and American localism".

${ }^{56}$ Cf. VITA, A justiça igualitária e seus críticos, p. 263. 


\section{Referências bibliográficas}

COHEN, Joshua. "For a democratic society". In: FREEMAN, Samuel (Ed.). The Cambridge companion to Rawls. Cambridge: Cambridge University Press, 2002.

FREEMAN, Samuel. Rawls. London and New York: Routledge, 2007.

GARGARELLA, Roberto. As teorias da justiça depois de Rawls: um breve manual de filosofia política. São Paulo: Martins Fontes, 2008.

KROUSE, Richard; MACPHERSON, Michael. "Capitalism, property-owning democracy, and the Welfare State". In: GUTMANN, Amy. Democracy and the Welfare state. Princeton, NJ: Princeton University Press, 1988.

KYMLICKA, Will. Contemporary political philosophy: an introduction. 2. ed. Oxford: Oxford University Press, 2002.

MACEDO, Stephen. "Property-owning plutocracy: inequality and American localism". In: HAYWARD, Clarissa Rile; SWANSTROM, Todd (Eds). Justice and American metropolis. Minneapolis, University of Minnesota Press, 2011. p. 33-58.

MEADE, James E. Efficiency, equality, and the ownership of property. London: Routledge, 2012.

O’NEALL, Martin. "Free (and fair) markets without capitalism: political values, principles of justice, and property-owning democracy". In: O'NEALL, Martin; WILLIAMSON, Thad (Eds). Property-owning democracy: Rawls and beyond. London, Blackwell. 2012. p. 75-100.

RAWLS, John. A theory of justice. Cambridge, Mass.: Harvard University Press, 1999.

Political liberalism. New York: Columbia University Press, 2005.

. Justice as fairness: a restatement. Cambridge, Mass.: Harvard University Press, 2001.

ROEMER, John E. "On public ownership". In: ROEMER, John E. Egalitarian perspectives: essays in philosophical economics. Cambridge and New York: Cambridge University Press, 1994. p. 267-286.

VAN PARIJS, Philippe (1992). "Basic income capitalism". Ethics, v. 102, n. 3 (April 1992), p. 465-484.

Real freedom for all. New York and Oxford: Clarendon Press, 2003.

VITA, Álvaro de. A justiça igualitária e seus críticos. 2. ed. São Paulo: Martins Fontes, 2007 